\title{
WAC journal
}

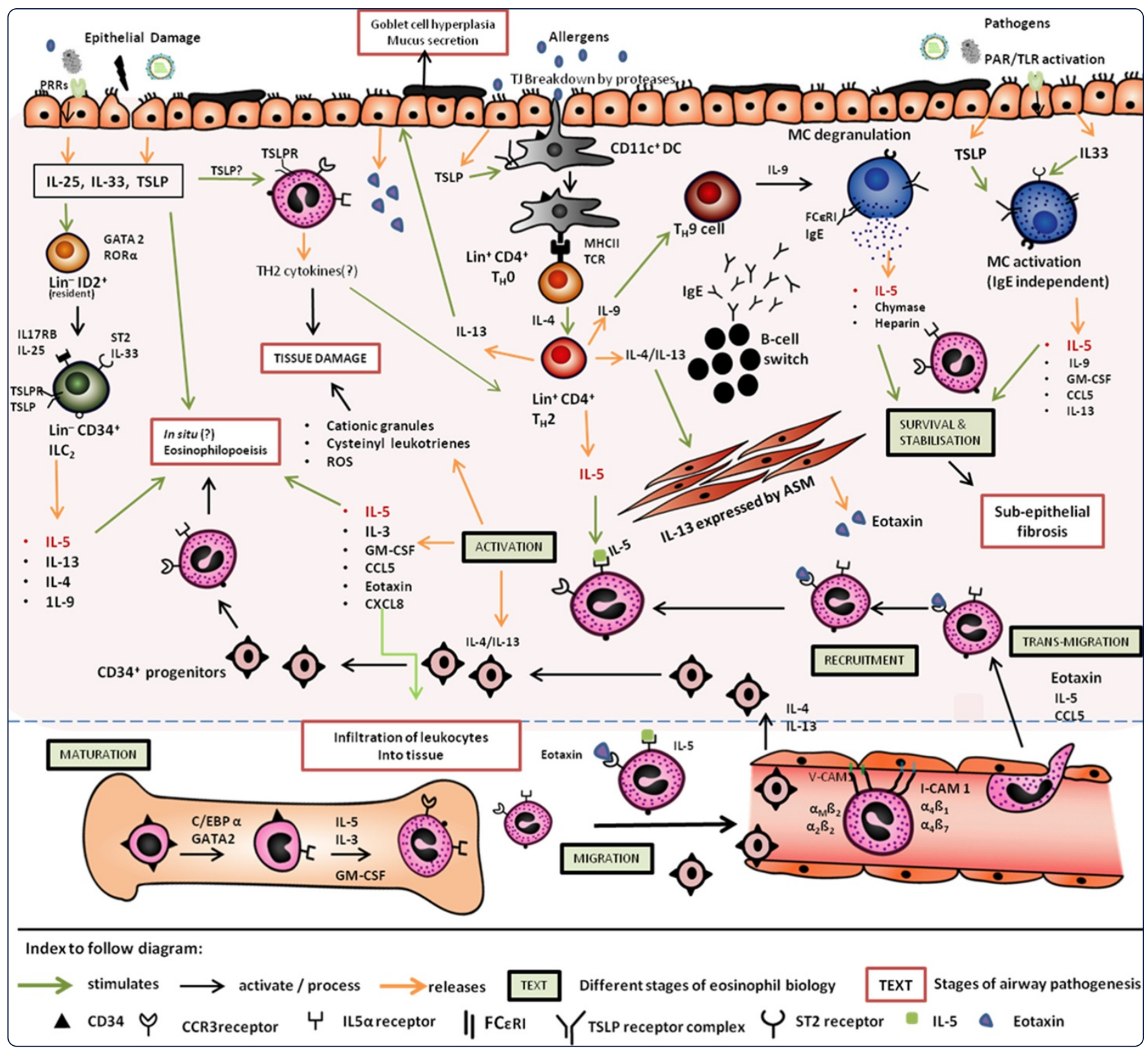

\section{Anti-IL5 therapy for asthma and beyond}

Mukherjee et al. 


\title{
Anti-IL5 therapy for asthma and beyond
}

\author{
Manali Mukherjee, Roma Sehmi and Parameswaran Nair
}

\begin{abstract}
Airway inflammation is considered to be the primary component contributing to the heterogeneity and severity of airway disorders. Therapeutic efficacies of diverse novel biologics targeting the inflammatory pathways are under investigation. One such target is IL-5, a type-1 cytokine that is central to the initiation and sustenance of eosinophilic airway inflammation. Over the past decade, anti-IL5 molecules have been documented to have mixed therapeutic benefits in asthmatics. Post hoc analyses of the trials reiterate the importance of identifying the IL-5-responsive patient endotypes. In fact, the currently available anti-IL 5 treatments are being considered beyond asthma management; especially in clinical complications with an underlying eosinophilic pathobiology such as hypereosinophilic syndrome (HES) and eosinophilic granulomatosis and polyangitis (EGPA). In addition, closer analyses of the available data indicate alternative mechanisms of tissue eosinophilia that remain uncurbed with the current dosage and delivery platform of the anti-IL5 molecules.

Keywords: Eosinophil, IL-5, Eosinophilic asthma, Hypereosinophilic syndrome (HES), Churg-strauss syndrome, Chronic bronchitis, Eosinophilic granulamatosis and polyangitis (EGPA), Chronic obstructive pulmonary disorder (COPD),

Mepolizumab, Reslizumab, Benralizumab
\end{abstract}

\section{Introduction}

The past ten years have witnessed the development and evaluation of a number of biologics that target the Th2 cytokines involved in asthma pathophysiology, particularly those that are associated with eosinophils in the airway. Eosinophils play a key role in the pathobiology of several airway disorders presenting with chronic inflammatory pathology such as asthma [1,2], chronic obstructive pulmonary disorder (COPD) [3], eosinophilic granulamatosis and polyangitis (EGPA) [4], and hypereosinophilic syndrome (HES) [5]. Targeting Interleukin-5 (IL-5) in asthma, the central protagonist in eosinophilia (discussed in details later), was a logical derivative post promising results in animal models $[6,7]$ and initial screenings in patients $[8,9]$. Deliberation arises from the mixed response of anti-IL- 5 trials conducted in different asthmatic populations that document a healthy reduction in circulating eosinophils, but without much significant improvement in other clinical indices of disease severity (extensively reviewed in [10-12]). Again in a recent review, anti-IL-5 therapy has been conjectured to be effective in long-term management of HES

\footnotetext{
* Correspondence: parames@mcmaster.ca

St Joseph's Healthcare \& Department of Medicine, Firestone Institute for Respiratory Health, McMaster University, 50 Charlton Avenue East, Hamilton, Ontario L8N 4A6, Canada
}

(C) 2014 Mukherjee et al.; licensee BioMed Central Ltd. This is an Open Access article distributed under the terms of the Creative Commons Attribution License (http://creativecommons.org/licenses/by/4.0), which permits unrestricted use, distribution, and reproduction in any medium, provided the original work is properly credited. The Creative Commons Public Domain Dedication waiver (http://creativecommons.org/publicdomain/zero/1.0/) applies to the data made available in this article, unless otherwise stated.

patients [5]. The current review will critically evaluate the documented outcomes of the conducted clinical trials to date and subsequently assess the therapeutic implications of anti-IL-5 therapy in treating airway disorders with an aberrant eosinophilic pathobiology.

\section{Eosinophil biology and the role of IL-5}

A robust literature now support eosinophils to be pleiotropic, multifunctional leukocytes that facilitate the 'innate' response against extraneous agents in the airway, modulate the downstream 'adaptive' immunity cascade, maintain local immunity/inflammation and as the end-stage effector cells that can cause tissue damage via release of granule proteins, reactive oxygen species and cysteinyl leukotrienes (reviewed in $[2,13])$. In eosinophil biology (refer to Figure 1), IL-5 plays a central role in the production, mobilization, activation, recruitment, proliferation, survival and suppression of apoptosis in eosinophils at the site of inflammation (reviewed in, $[2,6,12,13])$, illustrated in a schematic diagram (Figure 1).

In 1996, a study reported that 'IL-5 deficient' mice failed to develop the characteristic eosinophilia and airway hyper-reactivity after ovalbumin-sensitization [7]. Soon after, 8 asthmatic patients demonstrated increase in airway eosinophil counts and methcholine $\mathrm{PC}_{20}$ (a provocative concentration of methcholine required to 


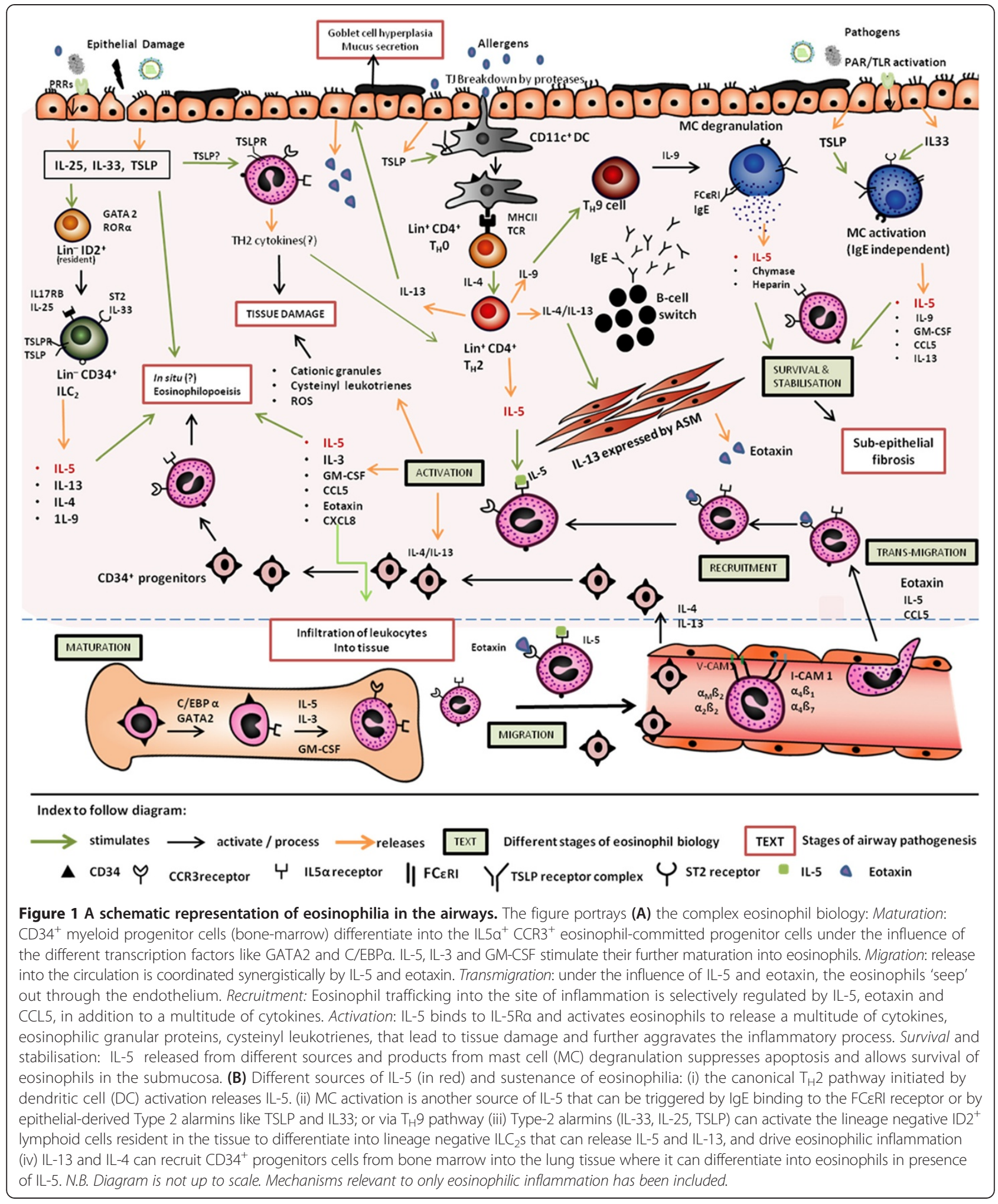

induce $20 \%$ reduction in the forced expiratory volume in 1 second, $\mathrm{FEV}_{1}$ ) when subjected to inhaled recombinant IL-5 [9]. Moreover, restraining sources of eosinophil recruitment and/or eosinophil-deficient animal models were observed to be healthy without any characteristic abnormalities [14]. As a logical derivative from the existing experimental and clinical evidences, several monoclonal antibodies (mAbs) were engineered to 
neutralize free circulating IL-5 and/or target IL-5 receptor alpha (IL5R $\alpha$ ) and are now in different phases of development $[10,12,15]$.

\section{A comparative analysis of the Anti-IL-5 trials: asthma}

As early as 1990, Bousquet et al., [8], correlated eosinophilia with asthma severity and demonstrated eosinophilic cation proteins (ECP) were associated with epithelial damage in 44 patients with asthma. A direct but modest correlation has been established between asthma severity, frequent exacerbations and the intensity of eosinophilia. Thereby, a sub-set of patients are being identified who suffer from 'severe refractory asthma', consequently accounting for a high socioeconomic burden and are considered to most benefit from an eosinophil-targeted therapy [1,10].

The last 15 years have documented several clinical trials that evaluate the therapeutic relevance of anti-IL-5 biologics in asthma treatment and symptom management (refer to Table 1). As evident from the outcome summary tabulated in Table 1, Mepolizumab, a humanized mAb (IgG1) with a high affinity for binding free IL-5 (which further prevents its binding to the receptor, IL5R $\alpha$ ), is found to be effective in depleting eosinophil numbers in blood and the airways. On the contrary, studies in mild-moderate asthmatics documented Mepolizumab to be ineffective in improving end-point clinical symptoms (refer to Table 1, [16,19,20]), therefore raising concern over the efficacy of IL-5 as a therapeutic intervention in asthma. However, by selecting patients with persistent blood $\left(>0.3 \times 10^{9} / \mathrm{L}\right)$ and sputum eosinophils $(\geq 3 \%)$ coupled with frequent history of exacerbations, two independent relatively small studies in 2009 documented a significant decrease in the exacerbation frequencies ( $\mathrm{P} \leq 0.02$ vs. placebo, both studies) and asthma control questionnaire (ACQ) scores $(\mathrm{P} \leq 0.02$, vs. placebo, both studies), with $750 \mathrm{mg}$ infusions of Mepolizumab $[21,22]$; in addition to a prednisone-sparing effect [21]. Similar reduction in exacerbation frequencies with corresponding decrease in peripheral blood eosinophils was reflected in a large, double-blinded, placebo-controlled, multi-centered study conducted in 2011 [23]. Based on the dose-response observations from the DREAM study [23], $75 \mathrm{mg}$ intravenous and $100 \mathrm{mg}$ subcutaneous doses were investigated in a recent Phase III trial, where significant reductions in exacerbation rates by $47 \%$ and $53 \%$ respectively $(\mathrm{P}<0.001$, vs. placebo) along with depletion of blood eosinophils were recorded [28]. The $100 \mathrm{mg}$ subcutaneous dose was reported in a parallel Phase III study to have a corticosteroid-sparing effect in a similar target population, with median percentage reduction of $50 \%$ in treatment group, along with $32 \%$ relative reduction in annual exacerbation rate $(\mathrm{p}=0.04$ vs placebo) [29]; a reduction though statistically significant, is less pronounced than that observed in the earlier study with higher dose and intravenous route of drug delivery [21,32]. The optimum dose, route and duration of therapy and persistence of beneficial effects for prednisone-dependent patients remain to be established.

Another anti-IL5 mAb (IgG $\left.\mathrm{m}_{4 / \mathrm{k}}\right)$ Reslizumab, showed similar reduction in sputum eosinophils, significant improvement in lung function $(\mathrm{P}=0.002$, vs. placebo $)$ and a trend towards improved asthma scores $(\mathrm{P}=0.054, v s$. placebo) in patients diagnosed with severe refractory eosinophilic asthma (see Table 1). Additionally, the authors observed the improvement in ACQ scores were most pronounced in patients with nasal polyps $(\mathrm{P}=0.012$, vs. placebo), [24] which reflected the observations of Gevaert et al., in 2003 [33]. There are recent reports of Phase III trials that demonstrate significant improvement in ACQ scores and $\mathrm{FEV}_{1}(\mathrm{p}<0.05$, vs. placebo) in moderate to severe asthmatics treated with $3.0 \mathrm{mg} / \mathrm{kg}$ of intravenous Reslizumab; charting a larger improvement in asthma control for subjects with baseline eosinophils $\geq 400$ cells $/ \mu$ l $[30,31]$.

IL5R $\alpha$ expressed by both mature eosinophils and eosi nophil-lineage progenitor cells [2], is targeted by Benralizumab (MEDI-563), a humanized, afucosylated mAb. Being afucosylated, this drug induces apoptosis in its target cells via enhanced antibody-mediated cellular toxicity (ADCC), and is considered to have an increased efficiency of eosinophil depletion comparative to the other anti-IL5 biologics [34]. The initial safety trial conducted by Busse et al., in 2010, documented no adverse events [25] and a further study by the same group showed $100 \%$ reduction of peripheral circulating eosinophils (Table 1) [26]. More recently, $100 \mathrm{mg}$ subcutaneous Benralizumab exhibited significant improvement in annual exacerbation rates, lung function and asthma score, with greater benefits seen in patients with blood eosinophil levels $\geq 400$ cells $/ \mu \mathrm{l}$ [27]. Currently, there are three clinical trials registered on http://clinicaltrials.gov (NCT01914757, NCT02075255, NCT01928771, last accessed 17/09/2014), where the drug is being assessed as an adjunct therapy for 'uncontrolled' asthma.

\section{Further assessment of anti-IL5 Trials: clinical insights}

The mixed outcomes from anti-IL-5 clinical trials highlight the need for careful endotyping of patients, since the therapy is deemed effective on those patients whose asthma is dependent on the eosinophilic inflammatory pathway [1]. The potential 'responders' to IL-5 therapy are patients who present with eosinophilia (blood $>0.3 \times 10^{9} / \mathrm{L},>3 \%$ sputum), are generally steroid-responsive, and suffer from frequent exacerbations. As evident from the DREAM study [23], the atopic status is inadequate for segregating 'responders' from the 'non-responders', since approximately $50 \%$ of the patients who responded to Mepolizumab had negative radioallergosorbent test to the four most common allergens. In addition, sub-sets of patients that are aspirin- 
Table 1 A comparative study of Anti-IL5 trials in Asthma

\begin{tabular}{|c|c|c|c|c|c|c|}
\hline $\begin{array}{l}\text { First author [ref] } \\
\text { year/ Drug }\end{array}$ & Disease (severity) & Study design & Dosage/ delivery & $\begin{array}{l}\text { Inclusion criteria: } \\
\text { Baseline eosinophil } \\
\text { count }\end{array}$ & Comments on eosinophilia & Outcome summary \\
\hline Leckie [16] 2000 & Mild atopic asthmatic & $\begin{array}{l}n=24 \\
m c, d b, p c\end{array}$ & $\begin{array}{l}\text { Single dose i.v., 2.5, } \\
10 \mathrm{mg} / \mathrm{kg}\end{array}$ & $\begin{array}{l}\text { - Not an inclusion } \\
\text { criteria }\end{array}$ & $\begin{array}{l}\text { - Day } 29 \text {, post-allergen } 10 \mathrm{mg} / \mathrm{kg} \text { dosage, } \\
\text { blood eos } 0.04 \times 10^{9} / \mathrm{L} \text { compared to } 0.25 \times\end{array}$ & - No significant effect on AHR \\
\hline \multirow[t]{3}{*}{ Mepolizumab } & \multirow{3}{*}{$\begin{array}{l}\mathrm{FEV}_{1} \geq 70 \% \\
\text { predicted }\end{array}$} & & & Baseline values: & 10\%/L placebo $(P<0.0001)$ & \multirow{3}{*}{$\begin{array}{l}\text { - No significant effect on late } \\
\text { asthmatic response to allergen } \\
\text { challenge }\end{array}$} \\
\hline & & & & $\begin{array}{l}\text { Sputum eos (\% } \\
\text { mean) }>11 \% \text { in all } \\
\text { groups }\end{array}$ & $\begin{array}{l}\text { - Day } 29, \text { post- allergen, } 10 \mathrm{mg} / \mathrm{kg} \text { dosage: } \\
0.7 \% \text { sputum eos compared to } 12.8 \% \\
\text { placebo ( } p=0.005 \text { ) }\end{array}$ & \\
\hline & & & & $\begin{array}{l}\text { Blood eos (counts } \times \\
\left.10^{9} / L\right)>0.2 \text { in all } \\
\text { groups }\end{array}$ & & \\
\hline Büttner [17] 2003 & $\begin{array}{l}\text { Mild to moderate } \\
\text { asthmatics }\end{array}$ & $\begin{array}{l}n=19 \\
m c, d b, p c\end{array}$ & Three monthly doses, i.v. & $\begin{array}{l}\text { No Baseline count/ } \\
\text { median } \mathrm{n} / \mathrm{a}\end{array}$ & $\begin{array}{l}\text { - Decrease in blood eos (median values from } \\
300 \text { to } 45 \text { per } \mathrm{mL}, \mathrm{P}<0.05 \text { vs. placebo) }\end{array}$ & - No asthma end-points were assessed \\
\hline \multirow[t]{2}{*}{ Mepolizumab } & \multirow[t]{2}{*}{$\begin{array}{l}\mathrm{FEV}_{1}>50-80 \% \\
\text { predicted }\end{array}$} & & \multirow[t]{2}{*}{$250 / 750 \mathrm{mg}$} & & \multirow{2}{*}{$\begin{array}{l}\text { - Decreased levels of serum ECP (median } \\
\text { values from } 15 \text { to } 5 \mathrm{mg}^{-1} \mathrm{~L}^{-1}, \mathrm{P}<0.05 \text { vs. } \\
\text { placebo) }\end{array}$} & $\begin{array}{l}\text { - T-cell sub-sets and T-cell cytokine } \\
\text { levels not altered }\end{array}$ \\
\hline & & & & & & - No sputum data \\
\hline Kips [18] 2003 & \multirow{10}{*}{$\begin{array}{l}\text { Moderate-severe } \\
\text { asthma, } \mathrm{FEV}_{1}>40- \\
80 \% \text {, predicted }\end{array}$} & \multirow[t]{10}{*}{$\begin{array}{l}n=32 \\
d b, p c, m c\end{array}$} & \multirow{10}{*}{$\begin{array}{l}\text { Rising single dose } \\
(0.03,0.1,0.3,1 \mathrm{mg} / \\
\mathrm{kg}) \text { i.v }\end{array}$} & $\begin{array}{l}\text { - Not included in the } \\
\text { inclusion criteria }\end{array}$ & - Dose dependently reduced circulating eos & \multirow{2}{*}{$\begin{array}{l}\text { - Significant increase in } \mathrm{FEV}_{1} \text { post } \\
24 \text { hours from dose range } \geq 0.3 \mathrm{mg} / \\
\mathrm{kg}(p=0.019)\end{array}$} \\
\hline \multirow[t]{9}{*}{ Reslizumab } & & & & Baseline value: & \multirow{2}{*}{$\begin{array}{l}\text { - Significant dose reduction with } 1 \mathrm{mg} / \mathrm{kg} \text { for } \\
30 \text { days post dosing }(p=0.05)\end{array}$} & \\
\hline & & & & $\begin{array}{l}\cdot \text { blood eos (counts } \times \\
\text { 10 } / \mathrm{L}) \text { : }\end{array}$ & & $\begin{array}{l}\text { - No significant changes in other } \\
\text { clinical indices }\end{array}$ \\
\hline & & & & Placebo:0.45 \pm 0.16 & \multirow{7}{*}{$\begin{array}{l}\text { - No significant trend in changes of sputum } \\
\text { eos were observed between groups due to } \\
\text { the wide variability in baseline counts } \\
\text { between the groups }\end{array}$} & \\
\hline & & & & $0.3 \mathrm{mg} / \mathrm{kg}: 0.28 \pm 0.04$ & & \\
\hline & & & & $1.0 \mathrm{mg} / \mathrm{kg}: 0.25 \pm 0.04$ & & \\
\hline & & & & • Sputum eos (\% mean) & & \\
\hline & & & & Placebo:22.9 \pm 12.5 & & \\
\hline & & & & $0.3 \mathrm{mg} / \mathrm{kg}: 2.6 \pm 0.44$ & & \\
\hline & & & & $1.0 \mathrm{mg} / \mathrm{kg}: 5.5 \pm 3.92$ & & \\
\hline $\begin{array}{l}\text { Flood-page [19] } \\
2003\end{array}$ & Mild atopic asthma & $\begin{array}{l}n=24 \\
d b, p c \text {, parallel- }\end{array}$ & 3 i.v. doses of $750 \mathrm{mg}$ & $\begin{array}{l}\text { - Not included in the } \\
\text { inclusion criteria }\end{array}$ & $\begin{array}{l}\text { - Blood eos: significant reduction in wk } 4 \text { and } \\
10 \text { ( } P<0.02 \text {, vs. placebo })\end{array}$ & - Sputum eos not checked \\
\hline \multirow[t]{4}{*}{ Mepolizumab } & \multirow{4}{*}{$\begin{array}{l}\mathrm{FEV}_{1} \geq 70 \% \\
\text { predicted }\end{array}$} & & \multirow{4}{*}{$\begin{array}{l}\text { Mepolizumab/ per } \\
\text { month12- wk follow } \\
\text { up }\end{array}$} & Baseline value: & & \multirow{4}{*}{$\begin{array}{l}\text { - No change in clinical parameters, } \\
\text { FEV1, AHR }\end{array}$} \\
\hline & & & & $\begin{array}{l}\cdot \text { Blood eos (mean } \times \\
\left.10^{9} / \mathrm{L}\right) \text { : }\end{array}$ & \multirow[t]{2}{*}{$\begin{array}{l}\text { - Bone marrow: } 70 \% \text { reduction in mature eos } \\
(P=0.017)\end{array}$} & \\
\hline & & & & Group: 0.27 & & \\
\hline & & & & Placebo: 0.4 & $\begin{array}{l}\text { - BAL fluid eos: median reduction of } 79 \% \text { from } \\
\text { baseline ( } P=0.4 \text { vs. placebo) ns }\end{array}$ & \\
\hline
\end{tabular}


Table 1 A comparative study of Anti-IL5 trials in Asthma (Continued)

\begin{tabular}{|c|c|c|c|c|c|c|}
\hline $\begin{array}{l}\text { Flood-page [20] } \\
2007\end{array}$ & $\begin{array}{l}\text { Moderate persistent } \\
\text { asthmatics }\end{array}$ & $\begin{array}{l}n=362 \\
m c, d b, p c\end{array}$ & 3 i.v. doses of & $\begin{array}{l}\text { - Not included in the } \\
\text { inclusion criteria }\end{array}$ & $\begin{array}{l}\text { - Blood eos: Sustained significant } 80 \% \\
\text { reduction for both doses ( } p<0.001 \text { vs. } \\
\text { placebo) }\end{array}$ & $\begin{array}{l}\text { - No significant change in clinical end- } \\
\text { points }\end{array}$ \\
\hline \multirow[t]{3}{*}{ Mepolizumab } & \multirow[t]{3}{*}{$\begin{array}{l}\mathrm{FEV}_{1} \geq 50-80 \% \\
\text { predicted }\end{array}$} & & $\begin{array}{l}750 / 250 \mathrm{mg} \\
\text { Mepolizumab per }\end{array}$ & \multirow{3}{*}{$\begin{array}{l}\text { - Baseline blood eos } \\
\text { for all group } \\
\text { showed median } \\
\text { values } \geq 0.3 \times 10^{9} / \mathrm{L}\end{array}$} & \multirow{3}{*}{$\begin{array}{l}\text { - Sputum eos significant reduction from } \\
\text { baseline }(P=0.006,250 \mathrm{mg}, \mathrm{P}=0.004,750 \mathrm{mg})\end{array}$} & \multirow{3}{*}{$\begin{array}{l}\text { - Trend for a reduction in exacerbation } \\
\text { rate, ns } \\
\text { - Decrease in summary symptom } \\
\text { score vs. placebo for } 750 \mathrm{mg} \text { at wk } \\
12(P=0.032)\end{array}$} \\
\hline & & & & & & \\
\hline & & & 8- wk follow up & & & \\
\hline \multirow{9}{*}{$\begin{array}{l}\text { Nair [21] } 2009 \\
\text { Mepolizumab }\end{array}$} & \multirow{2}{*}{$\begin{array}{l}\text { Severe persistent } \\
\text { asthma with } \\
\text { Eosinophilia }\end{array}$} & \multirow{9}{*}{$\begin{array}{l}n=20 \\
d b, p c \text {, pilot study }\end{array}$} & \multirow{2}{*}{$\begin{array}{l}5 \text { i.v. doses of } 750 \mathrm{mg} \\
\text { per month. }\end{array}$} & \multirow{2}{*}{$\begin{array}{l}\text { - Yes. Inclusion } \\
\text { criteria - Sputum } \\
\text { eos }>3 \%\end{array}$} & \multirow{3}{*}{$\begin{array}{l}\text { - Significant reduction in blood eos after } 1 \text { st } \\
\text { dose }(49.5 / \mu l) \text {, last dose }(64.5 / \mu l) \text { and follow } \\
\text { up }(76.3 / \mu)(P<0.05) \text { vs. placebo, no } \\
\text { significant reduction from baseline }\end{array}$} & \multirow{3}{*}{$\begin{array}{l}\text { - Significant reduction in asthma } \\
\text { exacerbations with drug (1) } \\
\text { compared to placebo (12 in } 10 \\
\text { patients), } P<0.01\end{array}$} \\
\hline & & & & & & \\
\hline & \multirow{7}{*}{$\begin{array}{l}\mathrm{FEV}_{1} \% \text {, predicted } \\
\text { value (median } \pm \mathrm{SD}) \\
48 \pm 17 \text { (drug) } 52 \pm \\
13 \text { (placebo) }\end{array}$} & & \multirow{7}{*}{$\begin{array}{l}\text { Prednisone dosage } \\
\text { tapered after } 2^{\text {nd }} \\
\text { infusion }\end{array}$} & Baseline: & & \\
\hline & & & & - Blood eos; & & \multirow{2}{*}{$\begin{array}{l}\text { - } 83.8 \% \text { reduction in prednisone dose } \\
\text { vs. placebo }(P<0.04)\end{array}$} \\
\hline & & & & \multirow{2}{*}{$\begin{array}{l}\text { Drug: } 664 \pm 492.5 / \mu l \\
\text { placebo: } 352 \pm 253.7 / \mu l\end{array}$} & \multirow{5}{*}{$\begin{array}{l}\text { - Significant reduction in sputum eos after } 1^{\text {st }} \\
\text { dose }(0 \%) \text {, last dose }(1.3 \%) \text { and follow-up } \\
(0.3 \%)(P<0.05) \text { vs. placebo, no significant } \\
\text { reduction from baseline }\end{array}$} & \\
\hline & & & & & & \multirow{2}{*}{$\begin{array}{l}\text { - } \mathrm{FEV}_{1} \text { - significant improvement vs. } \\
\text { placebo, } \mathrm{P}<0.05\end{array}$} \\
\hline & & & & - Sputum eos: & & \\
\hline & & & & Drug group: $16.6 \%$ & & \multirow{2}{*}{$\begin{array}{l}\text { - ACQ: significant improvement from } \\
\text { baseline } P=0.01 \text {, vs. placebo }\end{array}$} \\
\hline & & & & Placebo: $4 \%$ & & \\
\hline \multirow[t]{2}{*}{ Haldar [22] 2009} & \multirow{7}{*}{$\begin{array}{l}\text { Refractory } \\
\text { eosinophilic severe } \\
\text { asthma }\end{array}$} & \multirow{7}{*}{$\begin{array}{l}\mathrm{n}=61 \\
\mathrm{db}, \mathrm{pc} \text {, parallel } \\
\text { study }\end{array}$} & \multirow[t]{7}{*}{$\begin{array}{l}12 \text { doses of } 750 \mathrm{mg} \\
\text { i.v. per month }\end{array}$} & $\begin{array}{l}\text { - Inclusion criteria - } \\
\text { Sputum eos }>3 \%\end{array}$ & \multirow{2}{*}{$\begin{array}{l}\text { - Blood eos: reduced by a factor of } 6.6 \text { from } \\
\text { baseline in drug group, compared to } 1.1 \text { in } \\
\text { placebo }(P<0.001)\end{array}$} & \multirow[t]{2}{*}{$\begin{array}{l}\text { - Reduction in number of exacerbation } \\
\text { over the course of } 50 \text { wks }(P=0.02)\end{array}$} \\
\hline & & & & Baseline: & & \\
\hline \multirow{5}{*}{ Mepolizumab } & & & & - Blood eos (x 109/L); & & \multirow{2}{*}{$\begin{array}{l}\text { - AQLQ score increase with drug } \\
(P=0.02 \text {, vs. placebo })\end{array}$} \\
\hline & & & & $\begin{array}{l}\text { Drug:0.32 } \pm 0.38 \\
\text { placebo: } 0.35 \pm 0.30\end{array}$ & \multirow{4}{*}{$\begin{array}{l}\text { - Sputum eos: reduced by a factor of } 7.1 \text { from } \\
\text { baseline in drug group, compared to } 1.9 \text { in } \\
\text { placebo ( } P=0.002)\end{array}$} & \\
\hline & & & & - Sputum eos: & & \multirow{3}{*}{$\begin{array}{l}\text { - No significant difference in group in } \\
\text { AHR, FEV } 1, A C Q\end{array}$} \\
\hline & & & & Drug: $6.84 \pm 0.64 \%$ & & \\
\hline & & & & Placebo:5.46 $\pm 0.75 \%$ & & \\
\hline Pavord [23] 2012 & \multirow{6}{*}{$\begin{array}{l}\text { Severe refractory } \\
\text { asthma with } \geq 2 \\
\text { exacerbations in past } \\
\text { year }\end{array}$} & $n=621$ & 3 doses s.c., at 4 wks & - Yes. Inclusion & - Blood eos (x109/L): at $52 \mathrm{wk}$, vs. placebo & \multirow{3}{*}{$\begin{array}{l}\text { - Exacerbation rates at all doses were } \\
39-52 \% \text { less than those in the } \\
\text { placebo group }(P<0.05 \text { vs. placebo) }\end{array}$} \\
\hline \multirow[t]{5}{*}{ Mepolizumab } & & $\begin{array}{l}\mathrm{db}, \mathrm{pc} \text {, parallel } \\
\text { study, mc }\end{array}$ & 75/250/750 mg & $\begin{array}{l}\text { criteria - sputum } \\
\text { eos }>3 \%\end{array}$ & $75 \mathrm{mg}: 0.22<0.0001,250 \mathrm{mg}: 0.14 \mathrm{p}<0.0001$ & \\
\hline & & (DREAM) & 52 wk & Blood eos $\geq 0.3 \times 10^{9} / \mathrm{L}$ & 750 mg:0.12 $p<0.0001$ & \\
\hline & & & & Baseline: & - Sputum eos (ratio): at 52 wk & - No changes in $\mathrm{FEV}_{1}, \mathrm{ACQ}, \mathrm{AQLQ}$ \\
\hline & & & & - Blood eos (x 109/L); & $75 \mathrm{mg}: 0.68, \mathrm{~ns}$ & \multirow{2}{*}{$\begin{array}{l}\text { - Lowest dose of } 75 \mathrm{mg} \text { was near to } \\
\text { the top of the dose response curve } \\
\text { w.r.t reduction of blood eosinophils }\end{array}$} \\
\hline & & & & $>0.2$, for all groups & $250 \mathrm{mg}: 0.35, \mathrm{~ns}$ & \\
\hline
\end{tabular}


Table 1 A comparative study of Anti-IL5 trials in Asthma (Continued)

\begin{tabular}{|c|c|c|c|c|c|c|}
\hline \multirow[t]{8}{*}{ Reslizumab } & \multirow[t]{8}{*}{$\begin{array}{l}\text { Poorly controlled } \\
\text { asthma, on high dose } \\
\text { ICS }\end{array}$} & \multirow[t]{8}{*}{$\begin{array}{l}n=106 \\
d b, p c \text {, parallel } \\
\text { study, }\end{array}$} & \multirow[t]{8}{*}{$\begin{array}{l}3.0 \mathrm{mg} / \mathrm{kg} \mathrm{sc} \text {, at } \\
\text { baselineand at Weeks } \\
4,8 \text {, and } 12\end{array}$} & $\begin{array}{l}\text { - Yes. Inclusion } \\
\text { criteria - Sputum } \\
\text { eos }>3 \%\end{array}$ & $\begin{array}{l}\text { - Significant reduction in blood eosinophils } \\
(P<0.0001 \text {, vs. placebo })\end{array}$ & $\begin{array}{l}\text { - Trend in reduction of asthma } \\
\text { exacerbations in drug group } \\
(p=0.083, n s)\end{array}$ \\
\hline & & & & Baseline: & \multirow[t]{7}{*}{$\begin{array}{l}\text { - } 95.4 \% \text { reduction in sputum eos compared to } \\
\text { placebo, } 38.7 \%(p=0.0068)\end{array}$} & $\begin{array}{l}\cdot \text { ACQ trend in favour of drug group } \\
(p=0.054)\end{array}$ \\
\hline & & & & $\begin{array}{l}\cdot \text { Blood eos, median } \\
\left(\times 10^{3} / \mu \mathrm{L}\right)\end{array}$ & & \multirow{2}{*}{$\begin{array}{l}\text { - Significant improvement in ACQ } \\
\text { score in patients with nasal polyps } \\
(p=0.012)\end{array}$} \\
\hline & & & & Drug: 0.5 & & \\
\hline & & & & Placebo: 0.5 & & \multirow{4}{*}{$\begin{array}{l}\text { - Significant reduction in } \mathrm{FEV}_{1} \text { in drug } \\
\text { group }(p=0.002, \text { vs. placebo) }\end{array}$} \\
\hline & & & & - Sputum eos (\%): & & \\
\hline & & & & Drug: 10.7 & & \\
\hline & & & & Placebo: 8.5 & & \\
\hline Busse [25] 2010 & Mild atopic asthma & \multirow{6}{*}{$\begin{array}{l}\mathrm{n}=44 \\
\mathrm{mc} \text {, safety in } \\
\text { open-label study }\end{array}$} & \multirow{6}{*}{$\begin{array}{l}\text { Single escalating } \\
\text { doses }(0.0003-3 \mathrm{mg} / \\
\mathrm{kg} \text {, over } 3- \\
30 \text { minutes })\end{array}$} & $\begin{array}{l}\text { No. this was a safety } \\
\text { study. }\end{array}$ & \multirow{3}{*}{$\begin{array}{l}\text { - Significant decrease in eos in dose- } \\
\text { dependent fashion from baseline to } 0.01 \pm \\
0.0 \times 10^{3} / \mu \mathrm{L}, 24 \text { hours post-dose }\end{array}$} & - Acceptable safety profile \\
\hline \multirow{5}{*}{$\begin{array}{l}\text { Benralizumab } \\
\text { (MEDI-563) }\end{array}$} & \multirow{5}{*}{$\begin{array}{l}\mathrm{FEV}_{1} \geq 80 \% \text { of } \\
\text { predicted }\end{array}$} & & & Baseline: & & \multirow[t]{5}{*}{ - No adverse reactions were noted. } \\
\hline & & & & - Blood eos: & & \\
\hline & & & & $\begin{array}{l}\text { Mean } \pm \text { SD, } 0.27 \pm \\
0.2 \times 10^{3} / \mu \mathrm{L}\end{array}$ & \multirow[t]{2}{*}{$\begin{array}{l}\text { - } 94 \% \text { patients on doses } \geq 03 . \mathrm{mg} / \mathrm{ml} \text { showed } \\
0-0.1 \times 10^{3} / \mu \mathrm{L} \text { blood eos. }\end{array}$} & \\
\hline & & & & - ECP levels (mean) & & \\
\hline & & & & $21.4 \pm 17.2 \mu \mathrm{g} / \mathrm{L}$ & $\begin{array}{l}\text { - ECP levels were reduced from baseline to } \\
10.3 \pm 7.0 \mu \mathrm{g} / \mathrm{L}, 24 \mathrm{hrs} \text { post-dosing }\end{array}$ & \\
\hline $\begin{array}{l}\text { Laviolette [26] } \\
2013\end{array}$ & Eosinophilic asthma & $\begin{array}{l}n=27 \\
m c, d b, p c\end{array}$ & $\begin{array}{l}\cdot \text { Cohort } 1 \text { - (i.v) } \\
1 \mathrm{mg} / \mathrm{kg} \text { single dose }\end{array}$ & $\begin{array}{l}\text { - Sputum eosinophil } \\
\text { counts of } \geq 2.5 \%\end{array}$ & \multirow{2}{*}{$\begin{array}{l}\text { - Significant reduction in sputum eosinophils, } \\
\text { airway eosinophil counts and 100\% } \\
\text { reduction in bone marrow and peripheral } \\
\text { blood }\end{array}$} & \multirow[t]{11}{*}{$\begin{array}{l}\text { - Additional clinical factors were not } \\
\text { measured }\end{array}$} \\
\hline \multirow[t]{10}{*}{ Benralizumab } & \multirow{10}{*}{$\begin{array}{l}\mathrm{FEV}_{1} \geq 65 \% \\
\text { predicted }\end{array}$} & & \multirow{10}{*}{$\begin{array}{l}\text { - Cohort II-100 mg, } \\
200 \text { mg, combined } 3 \\
\text { monthly (s.c). }\end{array}$} & Baseline: & & \\
\hline & & & & - Sputum eos (mean\%) & \multirow{2}{*}{$\begin{array}{l}\text { - Airway mucosal/submucosal eos: mean } \\
\text { reduction vs. placebo: }\end{array}$} & \\
\hline & & & & - Cohort 1: & & \\
\hline & & & & Placebo : 13.9 & Cohort I : (i.v.) $61.9 \%$ (ns) & \\
\hline & & & & Drug: 6.6 & Cohort II, combined (sc): $83.1 \%(p=0.0023)$ & \\
\hline & & & & - Cohort II: & - Induced sputum eos (mean\%) & \\
\hline & & & & Placebo: 34.1 & \multirow{2}{*}{$\begin{array}{l}\text { Cohort I: } 4.5 \% \text {, day } 21 \text { compared to } 20.8 \% \\
\text { placebo }\end{array}$} & \\
\hline & & & & $100 \mathrm{mg}: 10.5$ & & \\
\hline & & & & 200 mg: 4.9 & \multirow{2}{*}{$\begin{array}{l}\text { Cohort II: (combined) } 0.6 \% \text { at day } 28, \\
\text { compared to } 6.4 \% \text { placebo }\end{array}$} & \\
\hline & & & & Combined: 7.4 & & \\
\hline
\end{tabular}


Table 1 A comparative study of Anti-IL5 trials in Asthma (Continued)

\begin{tabular}{|c|c|c|c|c|c|c|}
\hline Castro [27] 2014 & $\begin{array}{l}\text { Uncontrolled asthma } \\
\text { ACQ-6 score } \geq 1.5\end{array}$ & & \multirow{2}{*}{$\begin{array}{l}\cdot 2 \mathrm{mg}, 20 \mathrm{mg} \\
100 \mathrm{mg} \text { sc for } \\
\text { eosinophilic patients } \\
(\mathrm{n}=324)\end{array}$} & \multirow{4}{*}{$\begin{array}{l}\text { - Subjects were } \\
\text { stratified based on } \\
\text { blood eos, Sputum } \\
\text { eos } \geq 2 \% \text {, FeNO > } \\
50 \mathrm{ppb}\end{array}$} & $\begin{array}{l}\text { - All doses reduced blood eos }<50 \text { cells } / \mu \text { l after } \\
\text { the first dosage }\end{array}$ & $\begin{array}{l}\text { - Significant improvement in } \mathrm{FEV}_{1} \text { and } \\
\text { ACQ-6 in eos subtype with all doses }\end{array}$ \\
\hline \multirow{3}{*}{ Benralizumab } & \multirow[t]{3}{*}{$\begin{array}{l}\text { Exacerbation } \geq 2 / \text { last } \\
\text { year }\end{array}$} & $\begin{array}{l}\text { (324- } \\
\text { eosinophilic, 282) }\end{array}$ & & & \multirow{2}{*}{$\begin{array}{l}\text { - In eosinophilic group, } 100 \text { mg sc improved } \\
\text { annual exacerbation rate by } 41 \%(p=0.096) \\
\text { vs. placebo, deemed significant; ns in non- } \\
\text { eosinophilic group, }\end{array}$} & \multirow[t]{3}{*}{$\begin{array}{l}\text { - High incidence of adverse reactions } \\
\text { in treatment arm }\end{array}$} \\
\hline & & $\begin{array}{l}\text { Phase llb } \\
\text { Db, pc, dose- }\end{array}$ & $\begin{array}{l}\cdot 100 \text { mg sc for non- } \\
\text { eosinophilic }(n=282)\end{array}$ & & & \\
\hline & & $\begin{array}{l}\mathrm{Db}, \mathrm{pc} \text {, dose- } \\
\text { ranging study }\end{array}$ & $\begin{array}{l}\cdot 7 \text { doses every } \\
4 \text { weeks }\end{array}$ & & $\begin{array}{l}\text { - Subgroup analysis showed greater } \\
\text { improvement with increased baseline blood } \\
\text { eos ( } 100 \mathrm{mg} \text { sc reduced exacerbations by } \\
70 \% \text { in patients } \geq 400 \text { cells/ } / \mu \mathrm{l}, \mathrm{p}=0.002 \text { ) }\end{array}$ & \\
\hline Ortega [28] 2014 & Severe asthma & $n=576$ & - Cohort 1 - 75 mg i.v. & - Blood eos $150 / \mu l$ at & - Reduction in eos by week 4 mainted & - Rate of exacerbations reduced by \\
\hline \multirow[t]{3}{*}{ Mepolizumab } & \multirow{2}{*}{$\begin{array}{l}\text { Recurrent } \\
\text { exacerbations, with } \\
\geq 2 \text { in previous year }\end{array}$} & $m c, d b, p c$ & $(n=191)$ & in previous year & througn the entre stuay & respectively ( $p<0.001$, vs. placebo) \\
\hline & & \multirow[t]{2}{*}{ Phase III } & $\begin{array}{l}\text { - Cohort } 2 \text { - } \\
100 \text { mg s.c. }(n=194)\end{array}$ & \multirow{2}{*}{$\begin{array}{l}\text { - No sputum eos } \\
\text { were accounted }\end{array}$} & - $83 \%$ reduction in i.v. group & \\
\hline & $\begin{array}{l}\text { ICS dose } \geq 880 \mu \mathrm{g} \\
\text { fluticasone } \\
\text { propionate }\end{array}$ & & $\begin{array}{l}\text { Every } 4 \text { weeks for } \\
32 \text { weeks }\end{array}$ & & $\begin{array}{l}\text { - } 86 \% \text { recution in s.c. group ( } p<0.001, \text { vs. } \\
\text { placebo) }\end{array}$ & $\begin{array}{l}\text { - Improvement in } \mathrm{FEV}_{1} \text { for both } \\
\text { groups }(p<0.05) \text { and asthma scores } \\
(p<0.001)\end{array}$ \\
\hline Bel [29] 2014 & $\begin{array}{l}\text { Severe eosinophilic } \\
\text { asthma } \\
\text { On } 5-35 \text { mg of dailv }\end{array}$ & $\begin{array}{l}n=135 \\
m c, d b, p c\end{array}$ & $\begin{array}{l}\cdot 100 \text { mg s.c. every } \\
4 \text { weeks for } \\
20 \text { weeks }\end{array}$ & $\begin{array}{l}\text { - Inclusion criteria did } \\
\text { not account } \\
\text { sputum eos }\end{array}$ & $\begin{array}{l}\text { - Drug significantly reduced blood eos by } \\
\text { week } 4 \text { and was maintained throughout } \\
\text { study ( } p<0.001)\end{array}$ & $\begin{array}{l}\text { - Median percentage decrease in OCS } \\
\text { from baseline - } 50 \% \text { in drug arm to } \\
\text { no reduction in placebo }(p=0.007)\end{array}$ \\
\hline \multirow{2}{*}{ Mepolizumab } & \multirow{2}{*}{$\begin{array}{l}\text { On } 5-35 \mathrm{mg} \text { of daily } \\
\text { OCS, and severe } \\
\text { exacerbations }\end{array}$} & \multirow[t]{2}{*}{ Phase III } & & \multirow[t]{2}{*}{$\begin{array}{l}\text { - Blood eos } 150 / \mu l \text { at } \\
\text { screening or } 300 / \mu l \\
\text { in previous year }\end{array}$} & & $\begin{array}{l}\text { - Relative reduction of } 32 \% \text { in annual } \\
\text { exacerbation rate despite lowering of } \\
\text { OCS in drug arm ( } p=0.04 \text {, vs. } \\
\text { placebo) }\end{array}$ \\
\hline & & & & & & $\begin{array}{l}\text { - Improvement in ACQ-5 score } \\
\qquad(p=0.004)\end{array}$ \\
\hline Corren [30] 2014 & $\begin{array}{l}\text { Moderate-severe } \\
\text { asthma }\end{array}$ & $\mathrm{n}=395$ (drug) & $\begin{array}{l}\cdot 3.0 \mathrm{mg} / \mathrm{kg} \text {, i.v., monthly } \\
\text { (for } 16 \text { weeks) }\end{array}$ & $\begin{array}{l}\text { - Inclusion criteria } \\
\text { doesnot include }\end{array}$ & $\begin{array}{l}\text { - Abstract does not document any reduction } \\
\text { in blood eos }\end{array}$ & $\begin{array}{l}\text { - Significant reduction in ACQ score in } \\
\text { drug arm }(p=0.04)\end{array}$ \\
\hline \multirow[t]{2}{*}{ Reslizumab } & $\mathrm{ACQ} \geq 1.5$ & $\mathrm{n}=97$ (placebo) & & sputum eos & & \\
\hline & $\begin{array}{l}\text { On medium dose ICS } \\
(\sim 440 \mu \mathrm{g} \text { fluticasone })\end{array}$ & $\begin{array}{l}\mathrm{db}, \mathrm{pc}, \mathrm{mc} \text {, Phase } \\
\text { III }\end{array}$ & & $\begin{array}{l}\text { - Study population } \\
\text { stratified by baseline } \\
\text { blood eos } \geq \text { or } \leq \\
400 \text { cells } / \mu \text { l }\end{array}$ & $\begin{array}{l}\text { - Only } 20 \% \text { of study population was } \\
\text { eosinophilic (or } \leq 400 \text { cells } / \mu \text { l) }\end{array}$ & $\begin{array}{l}\text { - } \mathrm{FEV}_{1} \text { improvement for overall } \\
\text { population by } 68 \mathrm{ml}, 270 \mathrm{ml} \text { for } \\
\text { eosinophilic patients ( } p=0.04 \mathrm{vs} \text {. } \\
\text { placebo), ns increase of } 33 \mathrm{ml} \text { in } \\
\text { non-eosinophilic patients }\end{array}$ \\
\hline Bjermer [31] 2014 & Eosinophilic asthma & $\begin{array}{l}n=311 \\
d b, p c \text {, parallel }\end{array}$ & $\begin{array}{l}\cdot 0.3-3.0 \mathrm{mg} / \mathrm{kg} \text {, i.v., } \\
\text { monthly (for } 16 \text { weeks) }\end{array}$ & $\begin{array}{l}\cdot \text { blood eos } \geq 400 \\
\text { cells } / \mu \text { l }\end{array}$ & $\begin{array}{l}\text { - eosinophil measurement was not } \\
\text { documented in the abstract }\end{array}$ & $\begin{array}{l}\cdot \text { overall improvement in FEV1 } \\
p \leq 0.024 \text {, ACQ score }(p \leq 0.03)\end{array}$ \\
\hline Reslizumab & $\mathrm{ACQ} \geq 1.5$ & Phase III & & $\begin{array}{l}\text { - sputum eos not } \\
\text { accounted }\end{array}$ & & $\begin{array}{l}\cdot \text { Higher dose - significant FEV } \\
\text { increase as early as } 4 \text { weeks }\end{array}$ \\
\hline
\end{tabular}

Index: eos= eosinophils; $\mathrm{db}=$ double-blind; $\mathrm{pc}=$ placebo-controlled; $\mathrm{mc}=$ multi-center; $\mathrm{sc}=$ single-centre; $\mathrm{FEV}{ }_{1}=$ peak expiratory flow i.v= intravenous; $\mathrm{s.c}=$ sub-cutaneous; wk= week; $\mathrm{ns}=$ non-significant; $\mathrm{ACQ}=\mathrm{Asthma}$ Control Questionnaire, ICS= inhaled corticosteroid, OCS= oral corticosteroid. 
sensitive/induced asthma or present with sinusitis might also benefit from anti-IL5 therapy [35].

Using 'sputum eosinophils' as a biomarker to identify IL5-treatment responsive patient-groups as well as a marker for its therapeutic outcome is a topic under debate [1]. Studies that considered patients with $\geq 2.5-3 \%$ sputum eosinophilia in their inclusion criteria, independently recorded significant improvements with asthma scores and lung function $[21,22]$ compared to others (see Table 1). Similarly post hoc analysis showed that patients treated with $1.0 \mathrm{mg} / \mathrm{kg}$ Reslizumab, with baseline sputum levels< $3 \%$ did not show improvement in the $\mathrm{FEV}_{1}$, (even with depleted peripheral eosinophil levels) [18]. In fact, sputum eosinophils do not correlate with a change in circulating eosinophil numbers in the severe prednisone-dependent asthmatic patients and the former is markedly reduced before an event of exacerbations [1].

Subcutaneous doses of Mepolizumab showed neither significant reduction in sputum eosinophils (for 75 and $250 \mathrm{mg}$ dosage groups) nor any relevant improvements in the symptom scores or lung function (see Table 1, [23]). The recent phase III trials documented depletion of blood eosinophils, significant improvement in asthma symptom scores and moderate reduction in exacerbation rates with lower $(100 \mathrm{mg}$ ) subcutaneous doses (refer to Table 1), without any indication of whether the luminal eosinophilia generally exhibited in the specific patient group was resolved or not [28,29]. In contrast, $750 \mathrm{mg}$ intravenous infusions in the previous two studies of similar disease profiles $[21,22]$, were able to reduce both circulating and sputum eosinophils, allow significant improvement in $\mathrm{ACQ}, \mathrm{FEV}_{1}$ and quality of life score along with pronounced reduction in exacerbations. This discrepancy may reflect the therapeutic significance of the drug delivery platform and dose used, a concern addressed in a recent editorial [32].

\section{Further assessment of Anti-IL5 trials: molecular insights}

The eosinophil biology is complex and outcomes from the anti-IL-5 clinical trials reiterate this. Many of the anti-IL-5 clinical trials (Table 1) document the presence of tissue eosinophilia in spite of nil/low circulating levels, post-treatment. Especially, both studies with Benralizumab showed $100 \%$ reduction of eosinophils in bone-marrow and peripheral blood, but presence of airway mucosal/sub-mucosal eosinophils [26] and detectable levels of ECP in the sputum [25], indicating an alternative mechanism to IL-5 for eosinophil initiation, recruitment, activation and survival in the tissues. Delving further, Haldar et al., [22] showed significant decrease $(\mathrm{P}<0.002)$ for both circulating blood and sputum eosinophils (see Table 1) in the Mepolizumab study group, which was not reflected in the paired bronchialbiopsy specimens (obtained before and after the study).
In context, antisense oligonucleotide therapy (TPI ASM8), developed to suppress the expression of surface receptors CCR3 (C-C chemokine receptor type 3 , binds eotaxin) and $\beta$ chain (shared receptor for IL-5, IL-3 and granulocyte macrophage-colony stimulating factor, GM-CSF) [36], reduced sputum eosinophil counts by $46 \%$; while a CCR3 antagonist was recently documented to show no effect of blood or sputum eosinophilia or to have any clinically improvement in moderate to severe asthmatics [37]. Scattered evidences $[2,11,38]$ instrument the presence of alternative pathways in situ, that can trigger, activate and maintain eosinophils in the sub-mucosal and mucosal surfaces, independent of the classical $\mathrm{T}_{\mathrm{H}} 2$ pathway activation triggers (refer to Figure 1).

Extraneous environment-derived factors including nonallergic sources like pathogens and epithelial damage can trigger the release of epithelium-derived 'Type-2 alarmins' IL-25, IL-33, and thymic stromal lymphopoeitin (TSLP, see Figure 1) $[15,38]$. IL-25 and IL-33 can initiate mast cell (MC) response (mostly sub-mucosal localization) that leads to the release of IL-5 and CCL5. In addition, the type- 2 alarmins activate the resident lineage negative, type 2 , innate lymphoid cells $\left(\mathrm{ILC}_{2} \mathrm{~s}\right)$ to release the classical $\mathrm{T}_{\mathrm{H}} 2$ cytokines IL-5, IL-13, IL-9, that directly or indirectly support eosinophil recruitment and survival in the tissues (refer to Figure 1) [15,38-41]. Again, in vitro experiments demonstrated TSLP in presence of pro-inflammatory stimuli IL1-beta/tumor necrosis factor alpha (mimicking an ongoing inflammatory state) activated MCs to release IL-5 and IL-13; thereby, suggesting subsidiary mechanisms that produce IL-5 and can promote eosinophil numbers in the inflamed parenchyma/airway lumen [42]. IL-13 (and IL-4 in airway smooth muscle, ASM) trigger the release of eotaxins from the ASM [43] and the bronchial epithelium [44] that promote recruitment of eosinophils and eosinophil progenitors (refer to Figure 1). Increased IL-13 and IL-4 can promote the homing of $\mathrm{CD}^{+} 4^{+}$haemopoietic progenitor cells into the airway parenchyma [45].

Evidence suggest that this mechanism maybe upstream of activation by epithelial cell-derived cytokines [46,47]. Understanding physiological processes that promote airway eosinophilia in severe asthma may be critical to the development of novel treatment modalities for optimal asthma control. Luminal eosinophilia in asthma arise as a result of (i) the recruitment of mature eosinophils from the periphery in response to locally elaborated chemoattractants such as eotaxin and/or (ii) the localized maturation of eosinophil lineage-committed progenitors, termed "in situ differentiation" in the presence of locally elaborated cytokines such as IL-5 $[48,49]$. That haemopoietic progenitors differentiate within the tissue is inferred from findings that there is increased recruitment of eosinophil progenitor cells into the airways in asthmatics [50]. In addition $\mathrm{CD}_{3} 4^{+}$cells extracted from human nasal polyp 
tissue and nasal explant tissue undergo IL-5 driven differentiation to form mature eosinophils [51,52]. In context, anti-IL5 mAbs reduce tissue and luminal eosinophils (see Table 1), and are most effective in severe prednisonedependent asthmatics with eosinophilic bronchitis [21]. These findings suggest that local eosinophilopoiesis may be a more dominant mechanism for the persistence of eosinophils in the airways of patients with moderate-to-severe asthma than chemokine-dependent (for e.g. eotaxin) recruitment of mature eosinophils. Whilst this remains to be determined, it may explain our recent findings where treatment with anti-CCR3 failed to clear luminal eosinophils likely because the treatment did not attenuate local differentiative processes [37].

Controlling the development of airway eosinophilia may involve targeting multiple factors that stimulate eosinophils recruitment and modulate local differentiative processes or prolonged tissue survival. A few conducted clinical trials with mAbs targeting IL-4 and IL-13 biology, similar to anti-IL-5, has met with a mixed response in improving clinical symptoms [10]. However, a combination therapy with drugs like Dupulimab (targets the receptor complex common both IL-4 and IL-13) [53] and an anti-IL-5 mAb could synergistically curb the mechanisms of in situ eosinophilia plausibly altered in severe asthmatics, that render the airways susceptible to maintain the clinical symptoms.

\section{Anti-IL-5 therapy for other lung eosinophilic disorders}

As evident from the on-going discussion, IL-5 and IL-5 receptor alpha (IL5R $\alpha)$ exhibit an undeniable eosinophil lineage-specificity. Indisputably, they have been considered as a potential therapeutic target in eosinophilic airway disorders.

\section{Hypereosinophilic syndrome (HES)}

HES is a heterogeneous rare disorder defined by the presence of $>1500$ eosinophils per $\mu \mathrm{L}$ of blood, persistent for $\geq$ 6 months, with eosinophil-related organ involvement or dysfunction and no identifiable secondary cause of eosinophilia [5]. Early case studies with HES patients show considerable improvement in disease symptoms, patient relief, and decrease in eosinophilia with $750 \mathrm{mg}$ intravenous Mepolizumab [5]. Table 2 summarizes an open-label study with 4 patients in 2004 [54] followed by a double-blinded, multi-centered clinical trial with Mepolizumab in 2008, where 41 out of 43 patients (on the experimental drug and tapering strength of prednisone), managed to maintain a circulating blood eosinophil count $<600 / \mu \mathrm{L}$, for $\geq 8$ weeks ( $\mathrm{p}<0.0001, v s$. placebo) [55]. Additionally, it could be an alternative to using high-dose OCS, otherwise prescribed to the patients diagnosed with T-lymphocyte variant of HES [56]. A number of studies are currently underway to evaluate other anti-IL5 molecules in addition to Mepolizumab as potential therapeutic interventions in HES. A study with
HES patients is projected to end in early 2017, which evaluates the safety and efficacy of Benralizumab (NCT02130 882 ) in these subjects (http://clinicaltrials.gov).

\section{Eosinophilic Granulomatosis and Polyangitis (EGPA)}

EGPA, earlier known as Churg-Strauss syndrome, is a rare form of vasculitis characterized by asthma and eosinophilia, with multi-organ involvement (lung, peripheral nerves, heart, gastrointestinal tract, skin), where systemic corticosteroid is the cornerstone of therapy $[4,60]$. Histology shows classic evidence of an eosinophilic inflammatory response in the airway tissue of these patients and hence Mepolizumab has been reasoned to be a potential corticosteroid-sparing therapy. A recent case study reported complete regression of asthma (discontinuation of inhaled therapy) and depletion of blood and airway eosinophils in a patient with refractory EGPA with monthly infusions of $750 \mathrm{mg}$ Mepolizumab [60]. Kim et al., 2010, reported a significant $(75 \%)$ reduction in circulating eosinophils with 4 monthly doses of $750 \mathrm{mg}$ (i.v) Mepolizumab, in a small open label trial with 7 patients, that allowed safe reduction of OCS from a mean dose of $18.8 \mathrm{mg}$ to $4.6 \mathrm{mg}$ [57]. In addition, Mepolizumab at the same dosage allowed complete remission in 8 out of 9 EGPA patients in a Phase II uncontrolled trial (detailed in Table 1) [58]. Though promising, further clinical investigations are necessary to ascertain the therapeutic benefit of Mepolizumab in EGPA and a large multicenter clinical trial is ongoing.

\section{Chronic eosinophilic pneumonia (CEP)}

Chronic eosinophilic pneumonia (CEP) is an idiopathic condition that presents with peripheral eosinophilia, eosinophilic infiltrates in the lung parenchyma and may occasionally be associated with asthma. Increased levels of IL-5 and release of cytotoxic granular proteins from eosinophils constitutes an important pathomechanism in pulmonary tissue damage observed in CEP [61]. Conventionally OCS therapy is used for treatment; however, an eosinophil-targeted therapy with Mepolizumab might result in steroid-sparing therapeutic benefit in CEP patients.

\section{Chronic bronchitis (in COPD)}

Chronic bronchitis is a primary component of COPD that encompasses a high level of heterogeneity. A sputum database analysis of 2443 patients with airway diseases, revealed one-fifth of the COPD patients experience eosinophilic bronchitis (EB). Additionally, EB was also associated with the severity of airflow obstruction in non-asthmatic COPD. 18\% COPD patients with frequent exacerbations were documented to have EB and associated eosinophilia. Targeting eosinophils and IL-5 levels with Mepolizumab may decrease exacerbation rates and improve lung functions for this sub-set of COPD patients [62], as documented for other eosinophil-driven airway 
Table 2 Anti-IL5 trials in eosinophilic lung disorders

\begin{tabular}{|c|c|c|c|c|c|c|}
\hline $\begin{array}{l}\text { First author } \\
\text { [ref]/year/ } \\
\text { drug }\end{array}$ & Disease (severity) & Study design & Dosage/ delivery & $\begin{array}{l}\text { Baseline eosinophil } \\
\text { count }\end{array}$ & Comments on eosinophilia & Outcome summary \\
\hline $\begin{array}{l}\text { Garrett [54]/ } \\
2003\end{array}$ & HES & \multirow[t]{2}{*}{$\begin{array}{l}\mathrm{n}=4 \\
\text { open label }\end{array}$} & \multirow{2}{*}{$\begin{array}{l}3 \text { doses } 10 \mathrm{mg} / \mathrm{kg} \text { or } \\
750 \mathrm{mg}(\mathrm{max}) \text { i.v. } \\
\text { every } 4 \text { wk }\end{array}$} & \multirow{2}{*}{$\begin{array}{l}\text { - Blood eos }>750 / \mu \mathrm{L} \\
\text { after an } 8 \text { wk pre- } \\
\text { treatment run in } \\
\text { period }\end{array}$} & \multirow[t]{2}{*}{$\begin{array}{l}\text { - Blood eos reduced in all patients, } \\
\text { sustained in } 12 \text { wk follow-up span }\end{array}$} & $\begin{array}{l}\text { - Symptoms and quality of life improved in all } \\
\text { patients }\end{array}$ \\
\hline Mepolizumab & Severe, uncontrolled & & & & & - Progressive improvements in $\mathrm{FEV}_{1}$ \\
\hline $\begin{array}{l}\text { Rothenberg } \\
{[55] / 2008}\end{array}$ & HES & \multirow{4}{*}{$\begin{array}{l}\mathrm{n}=85 \\
\mathrm{db}, \mathrm{pc}, \mathrm{mc} \text {, parallel } \\
\text { group study }\end{array}$} & \multirow[t]{4}{*}{$\begin{array}{l}750 \mathrm{mg} \text { i.v. at } 4 \text { wk } \\
\text { interval } 36 \text { wk study }\end{array}$} & \multirow{2}{*}{$\begin{array}{l}\text { - Blood eos }<1000 / \mu \mathrm{L} \\
\text { after a } 6 \text { week run-in } \\
\text { period with } \\
\text { prednisone therapy }\end{array}$} & \multirow{3}{*}{$\begin{array}{l}\text { - Blood eos }<600 / \mu \text { for } 8 \text { wks, } \\
\text { achieved in } 95 \% \text { patients in drug } \\
\text { group , } 45 \% \text { placebo, } p<0.0001\end{array}$} & \multirow{4}{*}{$\begin{array}{l}\text { - Primary end-point (reduction of prednisone to } \\
10 \mathrm{mg} \text { or less without clinical severity) was } \\
\text { reached } 84 \% \text { of patients in drug group, } 43 \% \\
\text { placebo, } p<0.0001\end{array}$} \\
\hline \multirow[t]{3}{*}{ Mepolizumab } & \multirow{3}{*}{$\begin{array}{l}\text { (patients negative for } \\
\text { FIP1L1-PDGFRA fusion } \\
\text { gene) }\end{array}$} & & & & & \\
\hline & & & & $\begin{array}{l}\text { Baseline (median all } \\
\text { patients): }\end{array}$ & & \\
\hline & & & & $\begin{array}{l}\cdot \text { Blood eos }\left(\times 10^{9} / \mathrm{L}\right): \\
0.447 \pm 0.694\end{array}$ & - Sputum eos not measured & \\
\hline $\begin{array}{l}\text { Roufosse [56]/ } \\
2010\end{array}$ & (T-lymphecytic variant) - & $\begin{array}{l}n=85 \\
d b, p c \text {, international } \\
\text { study }\end{array}$ & $\begin{array}{l}750 \mathrm{mg} \text { i.v. at } 4 \text { wk } \\
\text { interval } 36 \text { wk study }\end{array}$ & $\begin{array}{l}\text { - Controlled } \\
\text { eosinophil levels } \\
(<1000 / \mu L) \text { by OCS }\end{array}$ & $\begin{array}{l}\text { - Blood eos were maintained } \leq \\
600 / \mu \mathrm{L} \text { by L-HES (Mepolizumab } \\
\text { group) for } 8 \text { wks and during the }\end{array}$ & $\begin{array}{l}\text { - Significant lower mean daily prednisone dose } \\
\text { of } 4.64 \mathrm{mg} \text { in drug dosed group, compared to } \\
28.3 \mathrm{mg} \text { in placebo }(\mathrm{P}=0.014)\end{array}$ \\
\hline Mepolizumab & $\begin{array}{l}\text { (T-lymphocytic variant) - } \\
\text { recruitment based on T- } \\
\text { cell phenotyping and } \\
\text { profile negative for FIP1L1- } \\
\text { PDGFRA gene }\end{array}$ & study & & $\begin{array}{l}(<1000 / \mu \mathrm{L}) \text { by OCS } \\
\text { monotherapy at a } \\
\text { daily dose of } 20- \\
60 \mathrm{mg} \text {. }\end{array}$ & $\begin{array}{l}\text { group) for } 8 \text { wks and during the } \\
\text { entire length of the study } \\
\text { compared to placeb0 }\end{array}$ & $\begin{array}{l}\text { - Patients with low CCL17 levels were seen to } \\
\text { significantly maintain blood eos } \leq 600 \mu \mathrm{l}\end{array}$ \\
\hline Kim [57]/2010 & EGPA & $n=7$ & 4 monthly 750 mg (i.v) & \multirow{4}{*}{$\begin{array}{l}\cdot \text { Mean eos count } \\
3.4 \%\end{array}$} & \multirow{2}{*}{$\begin{array}{l}\text { - Reduction in eos count from } \\
2.9 \% \text { (mean) to } 0.4 \text { at wk } 16 \\
\text { (wash-out phase) }\end{array}$} & \multirow{2}{*}{$\begin{array}{l}\text { - Mean reduction in corticosteroid } 18.8 \mathrm{mg} \text { to } \\
4.6 \mathrm{mg}, \mathrm{P}<0.001\end{array}$} \\
\hline \multirow[t]{3}{*}{ Mepolizumab } & Mean $\mathrm{FEV}_{1} 76 \%$ predicted & \multirow{3}{*}{$\begin{array}{l}\text { open -label pilot } \\
\text { study }\end{array}$} & \multirow[t]{3}{*}{40 wk study } & & & \\
\hline & \multirow[t]{2}{*}{$\begin{array}{l}\text { Mean Prednisone dose } \\
12.9 \mathrm{mg}\end{array}$} & & & & \multirow[t]{2}{*}{ - Eos mean 3.8\% at wk 40} & $\begin{array}{l}\text { - Significant improvement of ACQ during study } \\
\text { and wash-out phase }\end{array}$ \\
\hline & & & & & & $\begin{array}{l}\text { - Patients clinically stable through study period, } \\
\text { but EGPA manifestations on cessation of test } \\
\text { drug }\end{array}$ \\
\hline \multirow[t]{4}{*}{$\begin{array}{l}\text { Moosig [58] } \\
2011 \\
\text { Mepolizumab }\end{array}$} & $\begin{array}{l}\text { Active refractory }(n=3) \text { or } \\
\text { relapsing }(n=7) \text { active } \\
\text { EGPA }\end{array}$ & \multirow[t]{4}{*}{$\begin{array}{l}\text { sc, phase II, } \\
\text { uncontrolled }\end{array}$} & \multirow[t]{4}{*}{$\begin{array}{l}750 \text { mg i.v. once } \\
\text { every } 4 \text { weeks ( } 9 \\
\text { infusions in total) }\end{array}$} & $\begin{array}{l}\text { - BVAS does not } \\
\text { include eos as a } \\
\text { criteria }\end{array}$ & \multirow{4}{*}{$\begin{array}{l}\text { - } 6 \text { patients ( } \geq 120 \text { cells } / \mu l) \text { showed } \\
\text { reduction in eos from their } \\
\text { respective baseline, maintained } \\
\text { throughout. }\end{array}$} & $\begin{array}{l}\text { - Disease extent dropped from 4at weel } 0 \text { to } 0 \\
\text { at week } 32(p=0.009)\end{array}$ \\
\hline & OCS $\geq 12.5$ mg/daily & & & \multirow{3}{*}{$\begin{array}{l}\text { - Variations in eos } \\
\text { levels ranged from } 13 \\
\text { - } 4282 \text { cells } / \mu \text { l }\end{array}$} & & \multirow{2}{*}{$\begin{array}{l}\text { - Eight patients achieved remission at week } 32 \\
\text { (primary end-point), BVAS score=0, } \\
\text { OCS }<7.5 \mathrm{mg} / \text { day }\end{array}$} \\
\hline & BVAS $\geq 3$ & & & & & \\
\hline & & & & & & - No relapse occurred \\
\hline
\end{tabular}


Table 2 Anti-IL5 trials in eosinophilic lung disorders (Continued)

\begin{tabular}{|c|c|c|c|c|c|c|}
\hline $\begin{array}{l}\text { Brightling [59] } \\
2014 \\
\text { Benralizumab }\end{array}$ & Moderate to severe & Phase II & \multirow{3}{*}{$\begin{array}{l}100 \text { mg s.c. every } \\
4 \text { weeks (three } \\
\text { doses), then every } \\
8 \text { weeks (five doses) } \\
\text { over } 48 \text { weeks }\end{array}$} & $\begin{array}{l}\text { - Inclusion criteria } \\
\text { Sputum eosinophils } \\
>3 \% \text { at screening or } \\
\text { past year }\end{array}$ & $\begin{array}{l}\text { - Significant reduction in both } \\
\text { sputum and blood eosinophil } \\
\text { levels at week } 4 \text {, and maintained } \\
\text { till week } 56\end{array}$ & $\begin{array}{l}\text { - No changes in acute exacerbation rates, lung } \\
\text { function or symptom score between treatment } \\
\text { and placebo arm at week } 56 \text { for overall } \\
\text { population }\end{array}$ \\
\hline \multirow{2}{*}{ Benralizumab } & $\begin{array}{l}\text { Exacerbations } \geq 1 \text { in } \\
\text { previous year }\end{array}$ & Mc, pb,db & & $\begin{array}{l}\text { - Sub-group analysis } \\
\text { stratified results based } \\
\text { on } \geq 150 \text { or } \geq 200 \\
\text { or } \geq 300 \text { eosinophils/ } \\
\mu \mathrm{l}\end{array}$ & $\begin{array}{l}\text { - Increase in blood and sputum } \\
\text { eos after final dose }\end{array}$ & $\begin{array}{l}\text { - non-significant decrease in exacerbation rate } \\
\text { compared with placebo in patients with } \\
\text { baseline eosinophil counts of } \geq 150 \text { cells } / \mathrm{uL}(p= \\
\left.0^{\circ} 84\right), \geq 200 \text { cells } / \mathrm{uL}\left(p=0^{\circ} 26\right) \text {, or } 300 \text { cells } / \mu l \\
\left(p=0^{\circ} 28\right)\end{array}$ \\
\hline & & & & & & $\begin{array}{l}\text { - Changes in } \mathrm{FEV}_{1} \text { at week } 56 \text { was significant in } \\
\text { patients with blood eosinophil counts } \geq 150 \\
\text { cells } / \mu \mathrm{L}\left(\mathrm{p}=0^{\circ} 031\right) \text { or } \geq 200 \text { cells/ } \mu \mathrm{L}\left(\mathrm{p}=0^{\circ} 035\right) \text {, } \\
\text { and non-significant in those with counts of } \geq \\
300 \text { cells } / \mu \mathrm{L}\left(\mathrm{p}=0^{\circ} 22\right)\end{array}$ \\
\hline
\end{tabular}

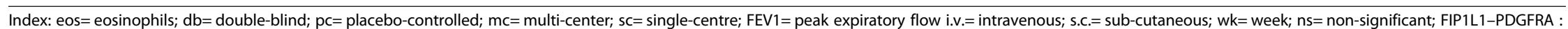
Fip 1-like 1/platelet-derived growth factor receptor a fusion; ACQ= Asthma Control Questionnaire; Birmingham Vasculitis Activity score= BVAS. 
disorders (discussed previously). However, as per the recent reports of Brightling and co-workers, no reduction in annual exacerbation rates was observed in moderate to severe COPD patients with eosinophilia (>3\% sputum eosinophils) when treated with a monthly/bimonthly subcutaneous dose of $100 \mathrm{mg}$ Benralizumab, even though the treatment effectively depleted both airway and circulating eosinophils (refer to Table 2) [59]. Nevertheless, online database (http://clinicaltrials.gov, last accessed 16/09/2014) enlists ongoing independent studies investigating efficacy and safety of Mepolizumab as an adjunct treatment in COPD management (registration number: NCT02105961); in COPD with EB (NC T01463644); reducing exacerbations in severe COPD (NCT02105948); and Phase III trials for Benralizumab in moderate to very severe COPD (NCT02155660, NC T02138916), addressing safety and efficacy of the drug.

\section{Summary}

The ongoing anti-IL5 clinical trials, show promise of a safe, effective treatment option for the severe 'eosinophilic' asthma endotype independent of their atopic status [63]. Beyond asthma, small pilot studies have documented their potential in treating HES and EGPA patients. IL-5 may not be the sole determinants of persistent airway eosinophilia. Recently described immune cells such as the $\mathrm{ILC}_{2} \mathrm{~S}$ and epithelium-derived type-2 alarmins that release $\mathrm{T}_{\mathrm{H}} 2$ cytokines like IL-13 may also play important rolesHence, targeting IL-5 and IL-13 to curb the eosinophil-derived clinical symptoms needs to be investigated in select patient-subtypes. Finally, while blood eosinophil count or other indirect assessments such as the eosinophil/lymphocyte ratios may help to identify an "eosinophilic phenotype" to initiate therapy with an anti-eosinophil biologic drug in patients with moderate asthma, this strategy may not be as effective as measuring sputum eosinophils to monitor response to therapy particularly in more severe systemic corticosteroiddependent asthmatic patients. The key to successful therapy would be to select the appropriate patient population. The mere presence of eosinophils in blood or sputum may not be sufficient. The patients who are likely to respond are those whose disease is truly largely dependent on eosinophil biology. Identification of these patients require clinical acumen, clinical criteria and demonstration of persistent (not transient) systemic and airway eosinophilia.

\footnotetext{
Abbreviations

mAb: Monoclonal antibodies; IL5Ra: Interleukin-5 receptor alpha; HES: Hypereosinophilic syndrome; EGPA: Eosinophilic granulamatosis and

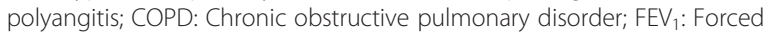
expiratory volume in 1 second; ACQ: Asthma control questionnaire; OCS: Oral corticosteroid; IL: Interleukin; ECP: Eosinophilic cationic protein; CCR: Chemokine chemokine receptor; TSLP: Thymus stromal lymphopoeitin.
}

\section{Competing interests}

PN is supported by a Canada Research Chair in Airway Inflammometry. He has received grants from GSK, AZ and Novartis for studies evaluating monoclonal antibodies and honoraria from Merck, Sanofi, BI, Galderma and Cipla. He does not have any conflicts related to this manuscript. MM and RS declare they have no competing interests.

\section{Authors' contributions}

PN conceived the idea. MM prepared the first draft. RS contributed to the development. All authors edited and reviewed the manuscript. All authors have approved the final version of the manuscript.

\section{Acknowledgements}

Dr Nair is supported by a Canada Research Chair in Airway Inflammometry. This manuscript is based on a lecture by Dr Nair at the WAO conference on Immunologics and Biologics, Chicago, IL, December 2013. Support for the dissemination of the WAO Immunotherapy and Biologics Online Monograph is provided by the following sponsors: Circassia, Boehringer-Ingleheim, and ORA Inc.

Received: 2 July 2014 Accepted: 30 September 2014 Published: 4 December 2014

\section{References}

1. Nair P: What is an "eosinophilic phenotype" of asthma? J Allergy Clin Immunol 2013, 132(1):81-83.

2. Rothenberg ME, Hogan SP: The Eosinophil. Annu Rev Immunol 2006 24(1):147-174

3. Hargreave FE, Leigh R: Induced sputum, eosinophilic bronchitis, and chronic obstructive pulmonary disease. Am J Respir Crit Care Med 1999 160(supplement_1):S53-S57.

4. Vaglio A, Buzio C, Zwerina J: Eosinophilic granulomatosis with polyangiitis (Churg-Strauss): state of the art. Allergy 2013, 68(3):261-273.

5. Busse WW, Ring J, Huss-Marp J, Kahn J-E: A review of treatment with mepolizumab, an anti-IL-5 mAb, in hypereosinophilic syndromes and asthma. J Allergy Clin Immunol 2010, 125(4):803-813.

6. Gleich GJ: Mechanisms of eosinophil-associated inflammation. J Allergy Clin Immunol 2000, 105(4):651-663.

7. Foster PS, Hogan SP, Ramsay AJ, Matthaei KI, Young IG: Interleukin 5 deficiency abolishes eosinophilia, airways hyperreactivity, and lung damage in a mouse asthma model. J Exp Med 1996, 183(1):195-201.

8. Bousquet J, Chanez P, Lacoste JY, Barnéon G, Ghavanian N, Enander I, Venge P, Ahlstedt S, Simony-Lafontaine J, Godard P, Michel F-B: Eosinophilic inflammation in asthma. New Engl J Med 1990, 323(15):1033-1039.

9. Shi H-Z, Xiao C-Q, Zhong D, Qin S-M, Liu Yl, Liang G-R, Xu HUI, Chen Y-Q, Long X-M, Xie Z-F: Effect of inhaled interleukin-5 on airway hyperreactivity and eosinophilia in asthmatics. Am J Respir Crit Care Med 1998, 157(1):204-209.

10. Hambly N, Nair P: Monoclonal antibodies for the treatment of refractory asthma. Curr Opin Pulm Med 2014, 20(1):87-94. doi:10.1097/ MCP.0000000000000007.

11. Pelaia G, Vatrella A, Maselli R: The potential of biologics for the treatment of asthma. Nat Rev Drug Discov 2012, 11(12):958-972

12. Garcia G, Taillé C, Laveneziana P, Bourdin A, Chanez P, Humbert M: Antiinterleukin-5 therapy in severe asthma. Eur Respir Rev 2013, 22(129):251-257.

13. Lee JJ, Jacobsen EA, McGarry MP, Schleimer RP, Lee NA: Eosinophils in health and disease: the LIAR hypothesis. Clin Exper Allergy 2010, 40(4):563-575.

14. Gleich GJ, Klion AD, Lee JJ, Weller PF: The consequences of not having eosinophils. Allergy 2013, 68(7):829-835.

15. Arron JR, Scheerens H, Matthews JG: Chapter One - Redefining Approaches to Asthma: Developing Targeted Biologic Therapies. In Advances in Pharmacology, Volume 66. Edited by David RW. Academic Press; 2013:1-49. doi: http://dx.doi.org/10.1016/B978-0-12-404717-4.00001-9

16. Leckie MJ, Brinke At, Khan J, Diamant Z, O'Connor BJ, Walls CM, Mathur AK, Cowley HC, Chung KF, Djukanovic R, Hansel TT, Holgate ST, Sterk PJ, Barnes PJ: Effects of an interleukin-5 blocking monoclonal antibody on eosinophils, airway hyper-responsiveness, and the late asthmatic response. Lancet 2000, 356(9248):2144-2148.

17. Büttner C, Lun A, Splettstoesser T, Kunkel G, Renz H: Monoclonal antiinterleukin-5 treatment suppresses eosinophil but not T-cell functions. Eur Respir J 2003, 21(5):799-803.

18. Kips JC, O'Connor BJ, Langley SJ, Woodcock A, Kerstjens HAM, Postma DS, Danzig M, Cuss F, Pauwels RA: Effect of SCH55700, a humanized 
anti-human interleukin-5 antibody, in severe persistent asthma. Am J Respir Crit Care Med 2003, 167(12):1655-1659.

19. Flood-Page PT, Menzies-Gow AN, Kay AB, Robinson DS: Eosinophil's role remains uncertain as anti-interleukin- 5 only partially depletes numbers in asthmatic airway. Am J Respir Crit Care Med 2003, 167(2):199-204.

20. Flood-Page P, Swenson C, Faiferman I, Matthews J, Williams M, Brannick L, Robinson D, Wenzel S, Busse W, Hansel TT, Barnes NC: A study to evaluate safety and efficacy of mepolizumab in patients with moderate persistent asthma. Am J Respir Crit Care Med 2007, 176(11):1062-1071.

21. Nair P, Pizzichini MMM, Kjarsgaard M, Inman MD, Efthimiadis A, Pizzichini E, Hargreave FE, O'Byrne PM: Mepolizumab for prednisone-dependent asthma with sputum eosinophilia. New Engl J Med 2009, 360(10):985-993.

22. Haldar P, Brightling CE, Hargadon B, Gupta S, Monteiro W, Sousa A, Marshall RP, Bradding P, Green RH, Wardlaw AJ, Pavord ID: Mepolizumab and exacerbations of refractory eosinophilic asthma. New Engl J Med 2009, 360(10):973-984

23. Pavord ID, Korn S, Howarth P, Bleecker ER, Buhl R, Keene ON, Ortega H, Chanez P: Mepolizumab for severe eosinophilic asthma (DREAM): a multicentre, double-blind, placebo-controlled trial. Lancet 2012 380(9842):651-659.

24. Castro M, Mathur S, Hargreave F, Boulet L-P, Xie F, Young J, Wilkins HJ, Henkel T, Nair P: Reslizumab for poorly controlled, eosinophilic asthma. Am J Respir Crit Care Med 2011, 184(10):1125-1132.

25. Busse WW, Katial R, Gossage D, Sari S, Wang B, Kolbeck R, Coyle AJ, Koike M, Spitalny GL, Kiener PA, Geba GP, Molfino NA: Safety profile, pharmacokinetics, and biologic activity of MEDI-563, an anti-IL-5 receptor a antibody, in a phase I study of subjects with mild asthma. J Allergy Clin Immunol 2010, 125(6):1237-1244. e1232.

26. Laviolette M, Gossage DL, Gauvreau G, Leigh R, Olivenstein R, Katial R, Busse WW, Wenzel S, Wu Y, Datta V, Kolbeck R, Molfino NA: Effects of benralizumab on airway eosinophils in asthmatic patients with sputum eosinophilia. J Allergy Clin Immunol 2013, 132(5):1086-1096. e1085.

27. Mario C, David LG, Christine KW, Yanping W, Deepak BK, Nestor AM, Donald GR: Benralizumab reduces exacerbations and improves lung function in adults with uncontrolled eosinophilic asthma. In B101 Asthma Pathogenesis. American Thoracic Society; 2014:A3699-A3699.

28. Ortega HG, Liu MC, Pavord ID, Brusselle GG, FitzGerald JM, Chetta A, Humbert M, Katz LE, Keene ON, Yancey SW, Chanez P, Investigators M: Mepolizumab treatment in patients with severe eosinophilic asthma. $N$ Engl J Med 2014, 371(13):1198-1207.

29. Bel EH, Wenzel SE, Thompson PJ, Prazma CM, Keene ON, Yancey SW, Ortega $H G$, Pavord ID, the SI: Oral glucocorticoid-sparing effect of mepolizumab in eosinophilic asthma. N Engl J Med 2014, 371(13):1189-1197.

30. Corren J, Weinstein S, Janka L, O'Brien C, Zangrilli J: A randomized phase 3 study $\mathrm{f}$ reslizumab efficacy in relation to blood eosinophil levels in patients with moderate to severe asthma. In European Respiratory Society Annual Congress: 10th September 2014. Munich, Germany: European Respiratory Journal; 2014.

31. Bjermer L, Lemiere C, Maspero J, Ciesielska C, O'Brien C, Zangrilli J: A randomized phase 3 study of the efficacy and safety of reslizumab in subjects with asthma with elevated eosinophils. In European Respiratory Society Annual Congress: 7th September 2014. Munich, Germany: European Respiratory Journal; 2014.

32. Nair P: Anti-interleukin-5 monoclonal antibody to treat severe eosinophilic asthma. N Engl J Med 2014, 371(13):1249-1251.

33. Gevaert P, Bachert C, Holtappels G, Novo CP, Van der Heyden J, Fransen L, Depraetere S, Walter H, van Cauwenberge P, Tavernier J: Enhanced soluble interleukin-5 receptor alpha expression in nasal polyposis. Allergy 2003, 58(5):371-379.

34. Ghazi A, Trikha A, Calhoun WJ: Benralizumab - a humanized mAb to IL-5Ra with enhanced antibody-dependent cell-mediated cytotoxicity - a novel approach for the treatment of asthma. Expert Opin Biol Ther 2011, 12(1):113-118.

35. Nair P, Dasgupta A, Brightling CE, Chung KF: How to diagnose and phenotype asthma. Clin Chest Med 2012, 33(3):445-457.

36. Gauvreau GM, Boulet LP, Cockcroft DW, Baatjes A, Cote J, Deschesnes F, Davis B, Strinich T, Howie K, Duong M, Watson RM, Renzi PM, O'Byrne PM: Antisense therapy against CCR3 and the common beta chain attenuates allergen-induced eosinophilic responses. Am J Respir Crit Care Med 2008, 177(9):952-958.

37. Neighbour H, Boulet LP, Lemiere C, Sehmi R, Leigh R, Sousa AR, Martin J, Dallow N, Gilbert J, Allen A, Hall D, Nair P: Safety and efficacy of an ora CCR3 antagonist in patients with asthma and eosinophilic bronchitis: a randomized, placebo-controlled clinical trial. Clin Exper Allergy 2014, 44(4):508-516.

38. Guy GB, Tania M, Ken RB: Eosinophils in the Spotlight: Eosinophilic airway inflammation in nonallergic asthma. Nat Med 2013, 19(8):977-979.

39. Licona-Limon P, Kim LK, Palm NW, Flavell RA: TH2, allergy and group 2 innate lymphoid cells. Nat Immuno/ 2013, 14(6):536-542.

40. Yu S, Kim HY, Chang Y-J, DeKruyff RH, Umetsu DT: Innate lymphoid cells and asthma. J Allergy Clin Immunol 2014, 133(4):943-950.

41. Walker JA, McKenzie ANJ: Development and function of group 2 innate lymphoid cells. Curr Opin Immunol 2013, 25(2):148-155.

42. Allakhverdi Z, Comeau MR, Jessup HK, Yoon BR, Brewer A, Chartier S, Paquette N, Ziegler SF, Sarfati M, Delespesse G: Thymic stromal lymphopoietin is released by human epithelial cells in response to microbes, trauma, or inflammation and potently activates mast cells. J Exp Med 2007, 204(2):253-258.

43. Moore PE, Church TL, Chism DD, Panettieri RA, Shore SA: IL-13 and IL-4 cause eotaxin release in human airway smooth muscle cells: a role for ERK. Am J Physiol Lung Cell Mol Physiol 2002, 282(4):L847-L853.

44. Matsukura S, Stellato C, Georas SN, Casolaro V, Plitt JR, Miura K, Kurosawa S, Schindler U, Schleimer RP: Interleukin-13 upregulates eotaxin expression in airway epithelial cells by a STAT6-dependent mechanism. Am J Respir Cell Mol Biol 2001, 24(6):755-761.

45. Punia N, Smith S, Thomson JV, Irshad A, Nair P, Sehmi R: Interleukin-4 and interleukin-13 prime migrational responses of haemopoietic progenitor cells to stromal cell-derived factor-1a. Clin Exp Allergy 2012, 42(2):255-264

46. Roma S, Kayla M, Anam I, Navneet P, Steven GS: Thymic stromal lymphopoietin (TSLP) and IL-33 prime the migrational responses of eosinophil-lineage committed progenitor cells. In A14 Interleukin-33: A Pivotal Mediator for Crosstalk between Innate and Adaptive Inflammatory Responses in the Lung. American Thoracic Society; 2013:A1005-A1005.

47. Hui CC, Asher I, Heroux D, Allakhverdi Z, Delespesse G, Denburg JA: Effects of thymic stromal lymphopoietin on cord blood progenitor cell differentiation and hemopoietic cytokine receptors expression. Allergy Asthma Clin Immunol 2011, 7:A24.

48. Pavord ID, Brightling CE, Woltmann G, Wardlaw AJ: Non-eosinophilic cor ticosteroid unresponsive asthma. Lancet 1999, 353(9171):2213-2214.

49. Fanat Al, Thomson JV, Radford K, Nair P, Sehmi R: Human airway smooth muscle promotes eosinophil differentiation. Clin Exp Allergy 2009, 39(7):1009-1017.

50. Sehmi R, Thomson JV, Catalli AE: Allergy and the bone marrow: transmigration pathways of hemopoietic progenitor cells from the bone marrow. In Allergy Frontiers: Classification and Pathomechanisms, Part 1. Edited by Pawankar P, Holgate S, Rosenwasser $\sqcup$. Japan: Springer; 2009:421-432.

51. Kim YK, Uno M, Hamilos DL, Beck L, Bochner B, Schleimer R, Denburg JA: Immunolocalization of CD34 in nasal polyposis. Effect of topical corticosteroids. Am J Respir Cell Mol Biol 1999, 20(3):388-397.

52. Cameron L, Christodoulopoulos P, Lavigne F, Nakamura Y, Eidelman D, McEuen A, Walls A, Tavernier J, Minshall E, Moqbel R, Hamid Q: Evidence for local eosinophil differentiation within allergic nasal mucosa: inhibition with soluble IL-5 receptor. J Immunol 2000, 164(3):1538-1545.

53. Wenzel S, Ford L, Pearlman D, Spector S, Sher L, Skobieranda F, Wang L, Kirkesseli S, Rocklin R, Bock B, Hamilton J, Ming JE, Radin A, Stahl N, Yancopoulos GD, Graham N, Pirozzi G: Dupilumab in Persistent Asthma with Elevated Eosinophil Levels. New Engl J Med 2013, 368(26):2455-2466.

54. Garrett JK, Jameson SC, Thomson B, Collins MH, Wagoner LE, Freese DK, Beck LA, Boyce JA, Filipovich AH, Villanueva JM, Sutton SA, Assa'ad AH, Rothenberg ME: Anti-interleukin-5 (mepolizumab) therapy for hypereosinophilic syndromes. J Allergy Clin Immunol 2004, 113(1):115-119.

55. Rothenberg ME, Klion AD, Roufosse FE, Kahn JE, Weller PF, Simon H-U, Schwartz LB, Rosenwasser L, Ring J, Griffin EF, Haig AE, Frewer PIH, Parkin $J M$, Gleich GJ: Treatment of patients with the hypereosinophilic syndrome with mepolizumab. New Engl J Med 2008, 358(12):1215-1228.

56. Roufosse F, de Lavareille A, Schandené L, Cogan E, Georgelas A, Wagner L, Xi L, Raffeld M, Goldman M, Gleich GJ, Klion A: Mepolizumab as a corticosteroid-sparing agent in lymphocytic variant hypereosinophilic syndrome. J Allergy Clin Immunol 2010, 126(4):828-835. e823.

57. Kim S, Marigowda G, Oren E, Israel E, Wechsler ME: Mepolizumab as a steroid-sparing treatment option in patients with Churg-Strauss syndrome. J Allergy Clin Immunol 2010, 125(6):1336-1343. 
58. Moosig F, Gross WL, Herrmann K, Bremer JP, Hellmich B: Targeting interleukin- 5 in refractory and relapsing churg-strauss syndrome. Ann Intern Med 2011, 155(5):341-343.

59. Brightling CE, Bleecker ER, Panettieri RA, Bafadhel M, She D, Ward CK, Xu X, Birrell C, van der Merwe R: Benralizumab for chronic obstructive pulmonary disease and sputum eosinophilia: a randomised, double-blind, placebo-controlled, phase 2a study. Lancet Respir Med 2014, Sept 5 2014, published online.

60. Kahn J-E, Grandpeix-Guyodo C, Marroun I, Catherinot E, Mellot F Roufosse F, Blétry O: Sustained response to mepolizumab in refractory Churg-Strauss syndrome. J Allergy Clin Immunol 2010, 125(1):267-270.

61. Akuthota P, Weller PF: Eosinophilic pneumonias. Clin Microbiol Rev 2012 25(4):649-660

62. Dasgupta A, Neighbour H, Nair P: Targeted therapy of bronchitis in obstructive airway diseases. Pharmacol Ther 2013, 140(3):213-222.

63. Ortega H, Chupp G, Bardin P, Bourdin A, Garcia G, Hartley B, Yancey S, Humbert M: The role of mepolizumab in atopic and nonatopic severe asthma with persistent eosinophilia. Eur Respir J 2014. 44(1):239-241.

doi:10.1186/1939-4551-7-32

Cite this article as: Mukherjee et al: Anti-IL5 therapy for asthma and beyond. World Allergy Organization Journal 2014 7:32.

\section{Submit your next manuscript to BioMed Central and take full advantage of:}

- Convenient online submission

- Thorough peer review

- No space constraints or color figure charges

- Immediate publication on acceptance

- Inclusion in PubMed, CAS, Scopus and Google Scholar

- Research which is freely available for redistribution 